\section{Blut ist nicht gleich Blut}

\author{
Ludwik Hirszfeld (5.8.1884-7.3.1954)
}

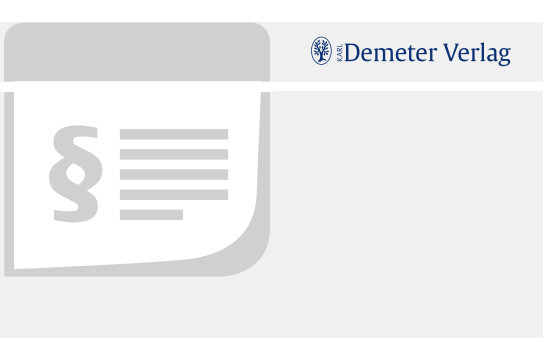

Das Blut eines jeden Menschen lässt sich einer Blutgruppe zuordnen. Obwohl es hier nur 4 Hauptgruppen gibt, wissen viele Menschen gar nicht, welcher sie angehören. Zum Glück lässt sich das heute innerhalb von Sekunden bestimmen. Wenn eine Bluttransfusion notwendig ist, kann die Bestimmung der Blutgruppe lebenswichtig werden, denn diese wird in der Regel immer gruppengleich durchgeführt, damit das fremde Blut vom eigenen Körper angenommen wird. Maßgeblich bestimmt und bezeichnet hat diese Gruppen mit den Ordnungsnamen $A, B, A B$ und $O$ der polnische Mediziner und Mikrobiologe Ludwik Hirszfeld. Seine Blutforschung fiel in eine Zeit, in der Forscher besonders daran interessiert waren, unterschiedliche menschliche Rassen zu bestimmen. So war auch Hirszfeld, selbst Jude, von der Rassenexistenz überzeugt und richtete seine Methoden der Serumbestimmung daraufhin aus. Als wahrer Glücksgriff für seine Blutforschung erwies sich der Erste Weltkrieg. Über Monate konnte Hirszfeld in Serbien die Unterschiede des Blutes verschiedener „Rassen“ untersuchen.

Berühmtes Zitat: (frei aus dem Polnischen) „Es gibt gute Kinder und es gibt unartige Kinder. Enkelkinder aber sind immer gut."

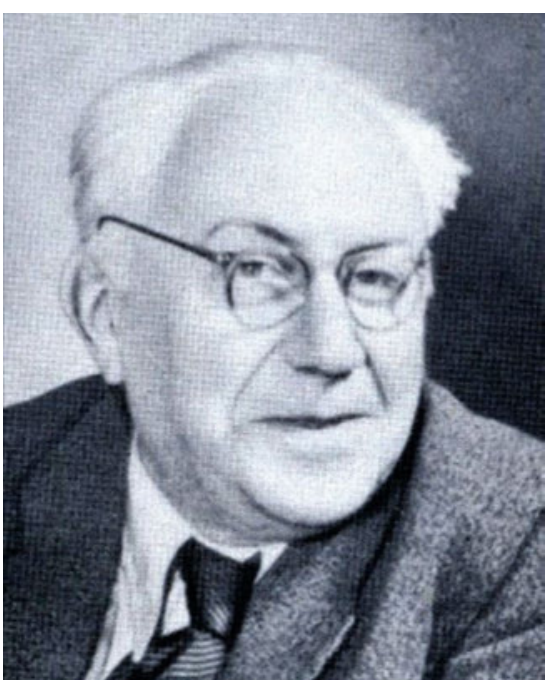

Ludwig Hirszfeld wurde als Sohn eines reichen Industriellen am 5. August 1884 in Warschau geboren. Nach Erwerb der Hochschulreife zog er 1902 nach Würzburg, um Medizin zu studieren. Innerhalb dieses Studiums wechselte er ans Hygiene Institut in Berlin und schloss hier 1907 mit seiner Dissertation über Agglutination - der Verklebung von Blutkörperchen - ab. Seine ganze Faszination galt der Erforschung des menschlichen Blutes. Bis 1911 arbeitete er am Institut für Immunologie in Heidelberg zusammen mit dem Serologen Emil von Dungern an der Bezeichnung und Benennung der menschlichen Blutgruppen. Eine seiner bedeutendsten Entdeckungen dieser Zeit war die Vererblichkeit von Blutgruppen. Um zu Habilitieren, ging Hirszfeld an die Universität Zürich, dozierte hier, arbeitete weiter an seinem Thema der Agglutination und beschäftigte sich außerdem besonders mit Gerinnungsvorgängen.

\section{Soldatenblut}

\section{für die Forschung}

Der Ausbruch des Ersten Weltkrieges bereitete Hirszfeld ungeahnte praktische Forschungsmöglichkeiten. Nach Bekanntwerden einer großen Flecktyphusepidemie

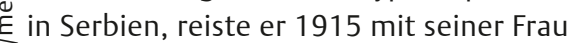
Hanna, ebenfalls Ärztin, nach Veljevo, um im Auftrag der serbischen Regierung die Infektionskrankheit zu erforschen und zu bekämpfen. Man stellte ihm ein eigenes Forschungslabor für Bakteriologie in der nordgriechischen Stadt Saloniki zur Verfügung. Hier lag zu dieser Zeit die sogenannte „Orientarmee“ der Entente-Mächte: Französische, britische, italienische, russische und serbische Truppen. Für Hirszfeld stellte dieser Umstand die Gelegenheit dar, in kürzester Zeit, an einem Ort das Blut unterschiedlicher „Rassen“ zu untersuchen und zu vergleichen. 8000 Soldaten entnahm er Blut und erkannte, dass Menschen unterschied-

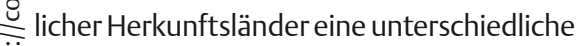
ڤ̂. Verteilung von Blutgruppen haben. Hirszfelds Ergebnisse begründeten einen neuen Forschungszweig: die Seroanthropologie.

\section{SCHON GEWUSST?}

Hirszfeld war 1920 vom Judentum zum Katholizismus konvertiert. Doch aufgrund seines Blutes blieb er für die Nationalsozialisten ein „Volljude“. Ausgerechnet jemandem, der am Zusammenhang zwischen Blut und "Rasse“ forschte, wurde sein eigenes Blut zum Verhängnis.

\section{Deportation aufgrund des Blutes}

Auf der Suche nach einer „Urblutgruppe“, vermutlich ohne es selbst zu wollen, teilte Hirszfeld „menschliche Rassen“ nach reinen und weniger reinen Blutgruppen ein und verurteilte bestimmte Mischungsverhältnisse. Nach dem Zweiten Weltkrieg musste sich Hirszfeld deswegen immer wieder gegen Rassismus-Vorwürfe wehren. Obwohl er selbst Opfer des Rassenwahns der Nationalsozialisten wurde.

Im Oktober 1939 trieben die Nazis Hirszfeld und seine Frau wie Hunderttausende andere Juden ins Warschauer Ghetto. 1942 gelang beiden mithilfe von Freunden die Flucht und sie retten sich so vor der unmittelbar bevorstehenden Deportation ins Vernichtungslager. Unerkannt und unter falschem Namen lebte Hirszfeld bis zum Kriegsende in Polen. Ab 1945 zog er nach Breslau, wo er zunächst eine medizinische Lehranstalt aufbaute und 1954 das Institut für Immunologie und Experimentelle Therapie der Polnischen Akademie der Wissenschaften mitbegründete. Im selben Jahr starb er mit erst 67 Jahren.

Dr. Christian Hardinghaus, Historiker, Medien- und Literaturwissenschaftler, Osnabrück

Lesen Sie an dieser Stelle in der nächsten Ausgabe einen Artikel über den Neurologen Sigmund Freund, den Begründer der Psychoanalyse, und finden Sie darin einen „Freudschen Verschreiber“. 